\title{
Influence of Dopant Type and Orientation of Silicon Anodes on Performance, Efficiency and Corrosion of Silicon-Air Cells with $\operatorname{EMIm}(\mathrm{HF})_{2.3}$ F Electrolyte
}

\author{
Yasin Emre Durmus, ${ }^{a, b, z}$ Simon Jakobi, ${ }^{a}$ Thomas Beuse, ${ }^{a}$ Özgür Aslanbas,,${ }^{a, b}$ \\ Hermann Tempel, ${ }^{\mathrm{a}}$ Florian Hausen,,${ }^{\mathrm{a}, \mathrm{b}}$ L. G. J. de Haart, ${ }^{\text {a,* }}$ Yair Ein-Eli,,$*$ \\ Rüdiger-A. Eichel, ${ }^{a, b}$ and Hans Kungl ${ }^{\mathrm{a}}$ \\ ${ }^{a}$ Fundamental Electrochemistry (IEK-9), Institute of Energy and Climate Research, Forschungszentrum Jülich GmbH, \\ 52425 Jülich, Germany \\ ${ }^{b}$ Institute of Physical Chemistry, RWTH Aachen University, 52074 Aachen, Germany \\ ${ }^{c}$ Department of Materials Science and Engineering, Technion-Israel Institute of Technology, Haifa 3200003 Israel
}

\begin{abstract}
Intermediate term discharge experiments were performed for $\mathrm{Si}$-air full cells using $\mathrm{As}-, \mathrm{Sb}$ - and $\mathrm{B}$-doped $\mathrm{Si}$-wafer anodes, with $\langle 100\rangle$ and $\langle 111\rangle$ orientations for each type. Discharge characteristics were analyzed in the range of 0.05 to $0.5 \mathrm{~mA} / \mathrm{cm}^{2}$ during $20 \mathrm{~h}$ runs, corrosion rates were determined via the mass-change method and surface morphologies after discharge were observed by laser scanning microscopy and atomic force microscopy. Corresponding to these experiments, potentiodynamic polarization curves were recorded and analyzed with respect to current-potential characteristics and corrosion rates. Both, discharge and potentiodynamic experiments, confirmed that the most pronounced influence of potentials - and thus on performance - results from the dopant type. Most important, the corrosion rates calculated from the potentiodynamic experiments severely underestimate the fraction of anode material consumed in reactions that do not contribute to the conversion of anode mass to electrical energy. With respect to materials selection, the estimates of performance from intermediate term discharge and polarization experiments lead to the same conclusions, favoring $\langle 100\rangle$ and $\langle 111\rangle$ As-doped Si-wafer anodes. However, the losses in the $\langle 111\rangle$ As-doped Si-anodes are by $20 \%$ lower, so considering the mass conversion efficiency this type of anode is most suitable for application in non-aqueous $\mathrm{Si}$-air batteries.

(C) The Author(s) 2017. Published by ECS. This is an open access article distributed under the terms of the Creative Commons Attribution 4.0 License (CC BY, http://creativecommons.org/licenses/by/4.0/), which permits unrestricted reuse of the work in any medium, provided the original work is properly cited. [DOI: 10.1149/2.0301712jes] All rights reserved.

(cc) BY
\end{abstract}

Manuscript submitted May 22, 2017; revised manuscript received July 21, 2017. Published August 5, 2017. age is metal-air batteries, which provide high specific energies and - when referring to $\mathrm{Zn}, \mathrm{Al}, \mathrm{Fe}$, or $\mathrm{Si}$ - are at the same time resource effective with respect to the availability and price of the anode materials. The theoretical specific energy of a Si-air cell, related to the anode mass only, is $8470 \mathrm{Wh} / \mathrm{kg}$. Using Si material in aqueous alkaline solutions, however, results in a severe corrosion reaction which is accompanied by intense hydrogen evolution. ${ }^{1-3}$ Despite the corrosion reaction, it is still feasible to build an alkaline $\mathrm{Si}$-air cell at a discharge potential around $1.1 \mathrm{~V}$, however, with sacrifice of huge amount of $\mathrm{Si}$ anode to corrosion. ${ }^{4-6}$

Therefore, new approaches to establish batteries on silicon materials have been put forward using ionic liquid electrolytes. One of the possible approaches is the usage of $\operatorname{EMIm}(\mathrm{HF})_{2.3} \mathrm{~F}$ electrolyte which possesses high conductivity, low viscosity and chemical stability in air. ${ }^{7-10}$ The proof of concept, that substantial discharge was possible when using EMIm $(\mathrm{HF})_{2.3} \mathrm{~F}$ electrolyte, was proposed in 2010 according to the following reactions: ${ }^{11}$

$$
\begin{array}{ll}
\text { Anode: } & \mathrm{Si}+12(\mathrm{HF})_{2} \mathrm{~F}^{-} \rightarrow \mathrm{SiF}_{4}+8(\mathrm{HF})_{3} \mathrm{~F}^{-}+4 \mathrm{e}^{-} \\
\text {Cathode: } \mathrm{O}_{2}+12(\mathrm{HF})_{3} \mathrm{~F}^{-}+4 \mathrm{e}^{-} \rightarrow 2 \mathrm{H}_{2} \mathrm{O}+16(\mathrm{HF})_{2} \mathrm{~F}^{-} \\
\mathrm{SiF}_{4}+2 \mathrm{H}_{2} \mathrm{O}+4(\mathrm{HF})_{2} \mathrm{~F}^{-} \rightarrow \mathrm{SiO}_{2}+4(\mathrm{HF})_{3} \mathrm{~F}^{-}
\end{array}
$$

Additionally, a screening of several anode materials - As-, Sband B-doped Si wafers - was performed, in which the cell potential at intermediate current densities as determined from potentiodynamic polarization measurements, was set as major criterion. The corrosion current densities as obtained by the Tafel fits from the polarization experiments for the different wafer types were also considered for the material selection. However, owing to the low corrosion rates, it played a minor role in identifying the most suitable wafer type for battery application as anode material. Subsequent detailed work - comprising the analysis of long run discharge behavior, ${ }^{11}$ the mechanisms that
One line of development in technologies for electrical energy stor-

lead to a discharge termination ${ }^{12,13}$ and the effects of humidity on the discharge characteristics ${ }^{14}$ - was focusing exclusively on cells with $\langle 100\rangle$ oriented As-doped Si anodes.

The development of Si-air batteries with $\mathrm{EMIm}(\mathrm{HF})_{2.3} \mathrm{~F}$ electrolyte is still in its early stages. Although the performance of this type of battery has been demonstrated with long run discharge experiments, delivering discharge capacities up to $26.7 \mathrm{mAh}$ (from $0.5 \mathrm{~cm}^{2}$ anode surface area), the limiting factors of the discharge are still under investigation. ${ }^{11}$ While end of discharge experiments provide the maximum discharge capacity values, an investigation of intermediate discharge experiments within a short time span is one of the steps for further understanding and development of the system. Such experiments allow for an analysis of additional parameters such as anode mass conversion efficiency while the cells are operated in a relatively stable potential window. Other possible factors contributing to the discharge limitation mechanisms are excluded at most and only the influence of the anode is investigated.

Following this approach, the present work aims to provide an additional information for a materials screening among $\mathrm{Si}$ wafer anodes for $\mathrm{Si}$-air batteries based on intermediate discharge profiles. Si anodes with three different types of dopants $\mathrm{As}, \mathrm{Sb}$ and $\mathrm{B}$, distinguishing $\langle 100\rangle$ and $\langle 111\rangle$ oriented wafers in each case, have been investigated. According to $\mathrm{Si}$-air full cells experiments fabricated with these six types of Si wafers during $20 \mathrm{~h}$, the results are evaluated with respect to (i) discharge potential characteristics at different current densities, (ii) the surface microstructures after the discharge experiments, and (iii) corrosion rates and anode mass conversion efficiencies. With respect to methodology of materials screening, the results on discharge potential characteristics and corrosion rates are compared with those obtained from an estimation based on concomitant potentiodynamic polarization experiments. Finally, a ranking with respect to performance, corrosion and specific energies that can be obtained from the different materials is discussed.

\section{Experimental}

*Electrochemical Society Member

${ }^{\mathrm{z} E}$-mail: y.durmus@fz-juelich.de
Materials.-Single crystalline silicon wafer anodes including As-doped $\langle 100\rangle(0.001-0.007 \Omega \mathrm{cm})$, As-doped $\langle 111\rangle(0.001-$ 
$0.010 \Omega \mathrm{cm})$, Sb-doped $\langle 100\rangle(0.007-0.020 \Omega \mathrm{cm})$, Sb-doped $\langle 111\rangle$ $(0.022-0.028 \Omega \mathrm{cm})$, B-doped $\langle 100\rangle(0.001-0.005 \Omega \mathrm{cm})$, and Bdoped $\langle 111\rangle(0.002-0.016 \Omega \mathrm{cm})$ were obtained by University Wafer. The Si wafers were cut into $11 \times 11 \mathrm{~mm}$ size resulting in average weights of $0.175 \mathrm{~g}$ for As-doped and $0.15 \mathrm{~g}$ for Sb- and B-doped $\mathrm{Si}$ wafers. Prior to electrochemical experiments, wafer surfaces were firstly treated with argon/oxygen plasma (PICO, Diener) to volatilize organic contaminations and secondly with argon/sulfur hexafluoride plasma to remove the native oxide layer. A room temperature ionic liquid $\operatorname{EMIm}(\mathrm{HF})_{2.3} \mathrm{~F}$ was provided by Morita Chemical Industries and used as electrolyte without further treatment. A commercial air electrode consisting of carbon black with manganese dioxide as catalyst (E4 type, Electric Fuel Ltd.) served as the cathode with a Teflon layer on the air side.

Cell setup.-Si-air cells for discharge experiments were constructed by using a single crystalline silicon wafer as anode, $\mathrm{EMIm}(\mathrm{HF})_{2.3} \mathrm{~F}$ as electrolyte, and a porous carbon electrode as cathode. The cell setup was adapted from Cohn et al. ${ }^{11}$ The surface areas of $\mathrm{Si}$ anode and air cathode were $0.44 \mathrm{~cm}^{2}$ and the electrolyte volume of the cell was $0.6 \mathrm{ml}$. For the three electrodes cell setup used in potentiodynamic polarization experiments, a Si wafer or an air cathode served as working electrode and a platinum wire as counter electrode. A ferrocene/ferrocenium $\left(\mathrm{Cp}_{2} \mathrm{Fe} / \mathrm{Cp}_{2} \mathrm{Fe}^{+}\right)$based gel electrode was prepared according to Shvartsev et al. ${ }^{15}$ and used as reference electrode. The surface area of the working electrode and the electrolyte volume was kept constant as for the cells used in the discharge experiments.

Electrochemical and surface characterizations.-Electrochemical galvanostatic and potentiodynamic polarization experiments were carried out with a Biologic VMP3 potentiostat. Prior to discharge process with different current densities for 20 hours, the cells were held at open-circuit potential (OCP) for 4 hours. The cells were kept in a climate chamber (Binder KMF115) to ensure constant ambient conditions $\left(25^{\circ} \mathrm{C}\right.$ with $50 \%$ relative humidity). In the polarization experiments, the potential of the electrode was scanned with a scan rate of $1 \mathrm{mV} / \mathrm{s}$ and the corrosion rates were calculated in the range of $\pm 20 \mathrm{mV}$ relative to OCP. The mass changes of silicon anodes were measured by using an analytical balance with an accuracy of $0.01 \mathrm{mg}$. The surface images of silicon wafers were obtained by using a confocal laser scanning microscope (OLS4100, Olympus Corp., Japan). All atomic force microscopy (AFM) images have been obtained with a Bruker Dimension ICON (St. Barbara, USA) using Tapping Mode conditions. Standard cantilever (PPP-NCHR, Nanosensors) with a nominal tip radius $<10 \mathrm{~nm}$ has been used as delivered.

Corrosion analysis.-The anode mass conversion efficiency is determined according to:

$$
\begin{gathered}
\eta(\%)=\left(\frac{\left(j \cdot A \cdot t_{d}\right)}{m_{t}}\right) \cdot\left(\frac{(n \cdot F)}{M_{S i}}\right)^{-1} \times 100 \\
m_{t}=m_{c}+m_{d}
\end{gathered}
$$

where the current density $\mathrm{j}$, area $\mathrm{A}$, discharge time $\mathrm{t}_{\mathrm{d}}$, number of electrons $\mathrm{n}$, the theoretical specific capacity $\left((\mathrm{n} \cdot \mathrm{F}) / \mathrm{M}_{\mathrm{Si}}\right)$ as well as equivalent mass consumed for electrochemical discharge $m_{d}$ are identical for all the Si materials. The corrosion mass $\mathrm{m}_{\mathrm{c}}$, is defined from the difference between the total anode mass change $m_{t}$, and the anode mass consumption emerging from the electrochemical discharge process $m_{d}$.

\section{Results}

Discharge behavior under varying current densities.-As-doped Si anodes.-The development of potentials with time under OCP for $4 \mathrm{~h}$ and subsequent discharge for $20 \mathrm{~h}$ of $\mathrm{Si}$-air batteries is shown in Figures 1a and 1b. As-doped $\langle 100\rangle$ and $\langle 111\rangle$ oriented Si anodes were discharged along with current densities from $0.05 \mathrm{~mA} / \mathrm{cm}^{2}$ to 0.5 $\mathrm{mA} / \mathrm{cm}^{2}$ in these experiments. The discharge characteristics of both types of anodes are very similar independent of the orientation. At the end of the OCP period, the potentials are stabilized between $1.5 \mathrm{~V}$ and $1.6 \mathrm{~V}$. After the initiation of the discharge, the cell potentials drop by $0.1 \mathrm{~V}$ to $1.4 \mathrm{~V}$ for low $\left(0.05 \mathrm{~mA} / \mathrm{cm}^{2}\right)$ and by $0.45 \mathrm{~V}$ to a discharge potential of $1.05 \mathrm{~V}$ for high $\left(0.5 \mathrm{~mA} / \mathrm{cm}^{2}\right)$ current densities. Along with time of discharge, the cell potentials slightly decrease. At the end of the $20 \mathrm{~h}$ discharge period, the potentials are by $0.3 \mathrm{~V}$ to 0.5 $\mathrm{V}$ less than at the beginning of the discharge for $0.05 \mathrm{~mA} / \mathrm{cm}^{2}$ and $0.5 \mathrm{~mA} / \mathrm{cm}^{2}$, respectively. The decrease of the potentials during the discharge period is not constant in time. While there is a relatively steep decrease of the potentials at the initial stage of the discharge, they seem to flatten out toward the end of the discharge profiles. The discharge time required to the transition toward the "flattening out stage" depends on the current densities. In case of high current densities $\left(0.4\right.$ and $\left.0.5 \mathrm{~mA} / \mathrm{cm}^{2}\right)$, the transition is visible in the potential vs. time profiles after $6 \mathrm{~h}$ discharge time. In contrast to that, the changes are slow and the transition extends toward the end of the discharge period under low current densities $\left(0.05\right.$ and $\left.0.1 \mathrm{~mA} / \mathrm{cm}^{2}\right)$.

Sb-doped Si anodes. - The potential vs. time characteristics of $\mathrm{Si}-$ air cells with $\langle 100\rangle$ oriented Sb-doped Si anodes (Fig. 1c) are qualitatively close to those of the cells with anodes from the As-doped materials. Under low current densities the discharge potentials are even quantitatively the same. Application of high current densities, however, results in significantly lower discharge potentials for the cells with Sb-doped compared those with the As-doped $\mathrm{Si}$ anodes. At the end of the $20 \mathrm{~h}$ discharge with $0.5 \mathrm{~mA} / \mathrm{cm}^{2}$, the potential is $0.47 \mathrm{~V}$ for the former, whereas it remains at values close to $0.61 \mathrm{~V}$ for the latter. Similar observations hold for the cells with Sb-doped Si with $\langle 111\rangle$ orientation in comparison to $\langle 111\rangle$ oriented As-doped Si (Fig. 1d). Only minor differences (mostly between 50 to $100 \mathrm{mV}$ ) with respect to the discharge profiles were found between cells with $\langle 100\rangle$ vs. $\langle 111\rangle$ oriented Sb-doped Si anodes.

B-doped Si anodes.-Discharge profiles of cells with $\langle 100\rangle$ oriented B-doped Si anodes are shown in Figure 1e. The potentials of these anodes stabilize at $1.15 \mathrm{~V}$ at the end of the OCP period. Along with low current density $\left(0.05 \mathrm{~mA} / \mathrm{cm}^{2}\right)$, the discharge potentials decrease from $1.05 \mathrm{~V}$ to $0.75 \mathrm{~V}$ over the discharge period. When applying high current densities $\left(0.5 \mathrm{~mA} / \mathrm{cm}^{2}\right)$ the discharge starts at a potential of $0.95 \mathrm{~V}$ and decreases to $0.45 \mathrm{~V}$ after $20 \mathrm{~h}$. In general, while the features of the potential profiles are similar to those of the cells with n-type $\mathrm{Si}$ anodes, there are quantitatively significant differences. Most marked differences are the substantially lower potentials compared to the cells with n-type $\mathrm{Si}$ anodes which show $0.4 \mathrm{~V}$ higher potentials under OCP and under low current densities. The potential differences are less pronounced along with higher current densities. When discharging with $0.5 \mathrm{~mA} / \mathrm{cm}^{2}$ the potential of the cell with $\langle 100\rangle$ oriented $\mathrm{B}$-doped $\mathrm{Si}$ anode is $0.45 \mathrm{~V}$ at the end of the discharge period. Under these conditions the corresponding potentials of cells with As- or Sb-doped Si anodes are $0.61 \mathrm{~V}$ and $0.47 \mathrm{~V}$, which are thus substantially higher for the former and only slightly higher for the latter than for the B-doped Si anode. Furthermore, the overall potential drop at the beginning of the discharge is less for the cells with $\langle 100\rangle$ oriented B-doped Si anode. The investigations also pointed out that the $\langle 111\rangle$ oriented B-doped anodes showed very similar discharge characteristics to $\langle 100\rangle$ oriented B-doped anodes (Fig. 1f).

Surface microstructure of anodes after discharge.-Laser Scanning Microscopy (LSM) images of the surface morphology of $\langle 100\rangle$ and $\langle 111\rangle$ oriented As- and Sb-doped (n-type) Si anodes after discharge with $0.1 \mathrm{~mA} / \mathrm{cm}^{2}$ are shown in Figure 2. The micrographs illustrate clear differences in the surface morphology for distinct orientations which are not directly expected because of the very similar discharge characteristics (Figs. 1a-1d).

Most pronounced differences between the surface characteristics of $\langle 100\rangle$ vs. $\langle 111\rangle$ oriented $\mathrm{Si}$ anodes have been observed when low discharge currents were applied. In the case of $\langle 100\rangle$ oriented Si anodes rather homogenous surfaces are found after discharge (Figs. $2 \mathrm{a}$ and $2 \mathrm{c}$ ) for both, As- and Sb-doped Si electrodes. In contrast to 

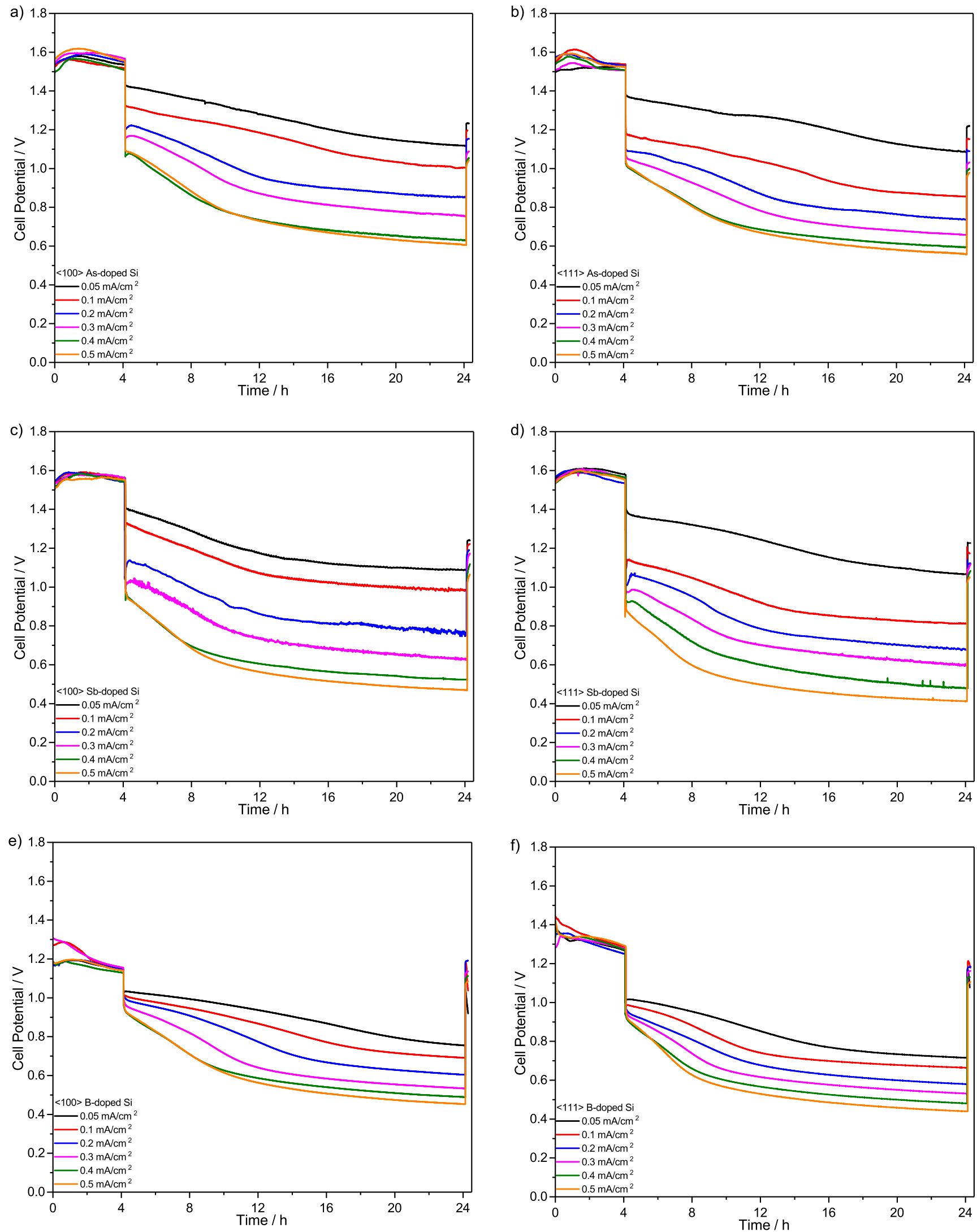

Figure 1. OCP and discharge profiles for $20 \mathrm{~h}$ in $\mathrm{Si}$-air full cells with $\mathrm{EMIm}(\mathrm{HF})_{2.3} \mathrm{~F}$ electrolyte under discharge current densities from $0.05 \mathrm{~mA} / \mathrm{cm}^{2}$ to 0.5 $\mathrm{mA} / \mathrm{cm}^{2}$ for a) $\langle 100\rangle$ oriented As-doped Si b) $\langle 111\rangle$ oriented As-doped c) $\langle 100\rangle$ oriented Sb-doped d) $\langle 111\rangle$ oriented Sb-doped e) $\langle 100\rangle$ oriented B-doped Si anode f) $\langle 111\rangle$ oriented B-doped Si anode. 

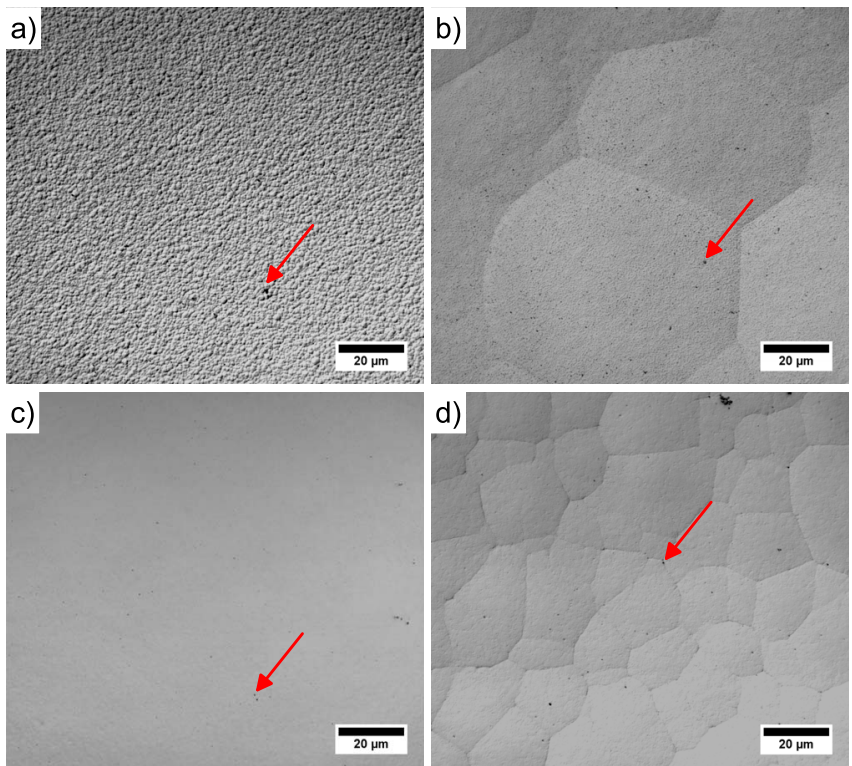

Figure 2. Surface morphology of As- and Sb-doped Si anodes after discharge at $0.1 \mathrm{~mA} / \mathrm{cm}^{2}$ for $20 \mathrm{~h}$ a) $\langle 100\rangle$ oriented As-doped Si. b) $\langle 111\rangle$ oriented As-doped Si. c) $\langle 100\rangle$ oriented Sb-doped Si. d) $\langle 111\rangle$ oriented Sb-doped Si. Red arrows indicate the pits that are formed on the surfaces in a non-regular fashion.

that the $\langle 111\rangle$ oriented $\mathrm{Si}$ electrodes exhibit a remarkable surface structure consisting of polygons (Figs. $2 b$ and $2 d$ ). Noteworthy, the surface morphologies of Sb-doped $\mathrm{Si}$ anodes are on the mesoscale very similar to those of As-doped $\mathrm{Si}$ anodes for corresponding orientations when discharged at $0.1 \mathrm{~mA} / \mathrm{cm}^{2}$ for $20 \mathrm{~h}$. Closer inspection of all types of electrodes reveals that very similar pits are formed across the surface in a non-regular fashion (as exemplarily indicated by arrows). These pores are too small to be analyzed further by LSM and thus, Atomic Force Microscopy (AFM) has been employed to gain insight into nano- and micrometer scale characteristics of the Si electrode surfaces. Within this manuscript we focus on As-doped Si electrodes to be investigated by AFM. Figure 3 depicts optical microscopy as well as AFM images of As-doped Si anodes with $\langle 100\rangle$ orientation. In agreement with the LSM images a smooth surface with some pits is observed in the optical microscopy image, as shown in Figure 3a. AFM reveals that the surface exhibits small round-shaped pits with typical dimensions of $1.0 \mu \mathrm{m}$ to $2.0 \mu \mathrm{m}$ in diameter and a depth of $10 \mathrm{~nm}$. Moreover, the AFM images illustrate that the pits are indeed lower parts of the surface and that the surface exhibits many more even smaller sized pits. At some places these structures conglomerate to larger structures as illustrated in Figure $3 \mathrm{~b}$ and are then visible in LSM or optical microscopy and exhibit a depth of up to $40 \mathrm{~nm}$. Interestingly, very few pillars are also present on the surface as apparent in Figures $3 \mathrm{~b}$ and $3 \mathrm{~d}$. The heights of these pillars are typically $150 \mathrm{~nm}$ according to the line profile (Fig. 3c) that was obtained from the Si surface through the dashed lines as shown in Figure $3 \mathrm{~b}$.

Figure 4 demonstrates that the typical polygon-like surface structure of $\langle 111\rangle$ oriented Si-wafers after $20 \mathrm{~h}$ discharge is also observed in optical microscopy (Fig. 4a). From the AFM image, it can be clearly seen that the walls forming the structure as observed on the mesoscale correspond to pillars on the surface (Fig. 4b). An even higher magnification (Fig. 4c) illustrates that such structures are composed of numerous particles with a typical size of 100-200 nm in width and 60-150 nm in height. Similar structures, however, much less in number, have also been observed for As-doped $\langle 100\rangle$ oriented Si electrodes (Fig. 3b). In the phase signal, depicted in Figure 4d and recorded simultaneously to the topography image, a contrast is only obtained at the edges of the particles and not between the surface (blue arrow) and the top part of the particles (white arrow).

The surface morphologies forming on B-doped (p-type) Si anodes are remarkably different from those found on n-type anodes after discharge with $0.1 \mathrm{~mA} / \mathrm{cm}^{2}$ (Fig. 5). For the B-doped Si anodes with $\langle 100\rangle$ orientation, a rather smooth surface is found, exhibiting only a few individual small pores as detectable with LSM (Fig. 5a). These observations are also confirmed by AFM of B-doped Si electrodes. The corresponding images are shown in the supplementary file (Fig. S1). In contrast, a higher discharge current of $0.3 \mathrm{~mA} / \mathrm{cm}^{2}$ or a $\langle 111\rangle$ surface

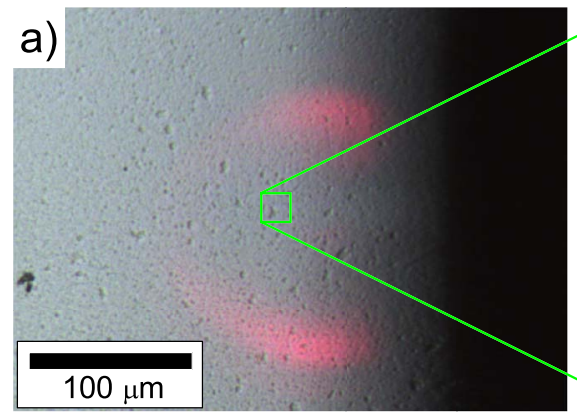

c)

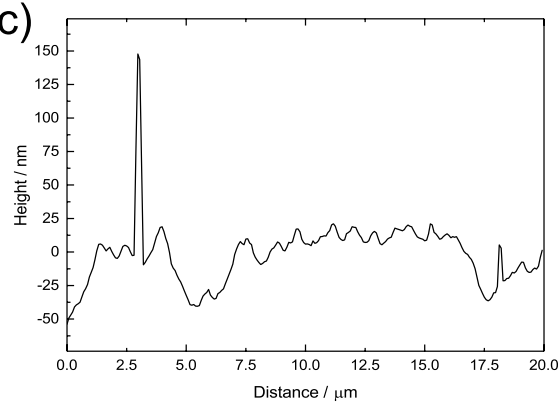

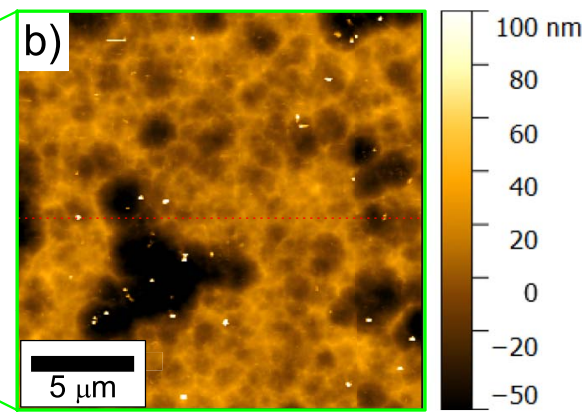

d)

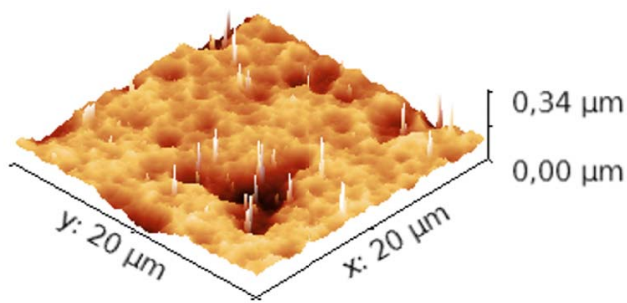

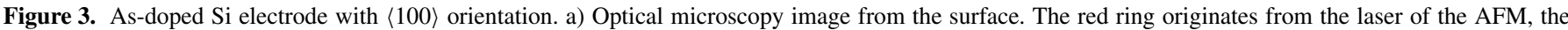

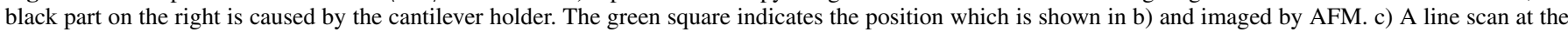

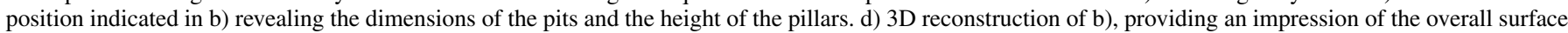
characteristics. 

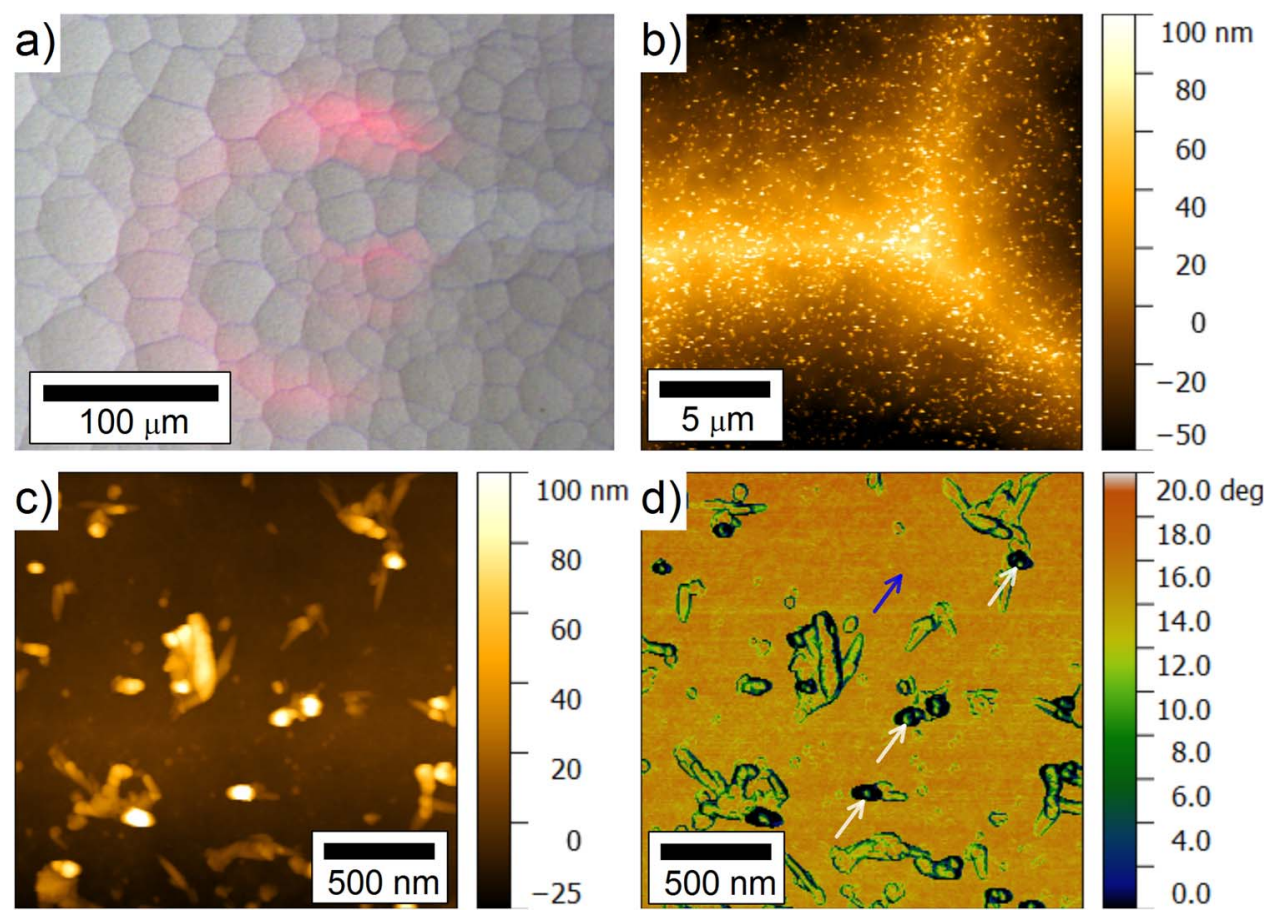

Figure 4. a) Optical microscopy image from the surface of As-doped Si electrode with $\langle 111\rangle$ orientation. b) Low magnification AFM image of a wall/boundary of polygon structures. c) High magnification AFM image of the wall/boundary. The axis had been chosen to enhance the contrast between smaller sized objects. d) Simultaneously recorded phase image of the high magnification AFM image shown in c). White arrows indicate the top of the particles and the blue arrow indicates the surface.

orientation leads to a less smooth surface structure corresponding to n-type Si electrodes on a mesoscopic scale (Figs. 5b-5d) in LSM images as well as on small scales as illustrated by AFM (Fig. S1). Additionally, the $\langle 111\rangle$ oriented B-doped samples show a grain like structure with relatively dense packed grains, whereas polygon like patterns, as present in the $\langle 111\rangle$ oriented As-doped $\mathrm{Si}$ anodes have not been observed.
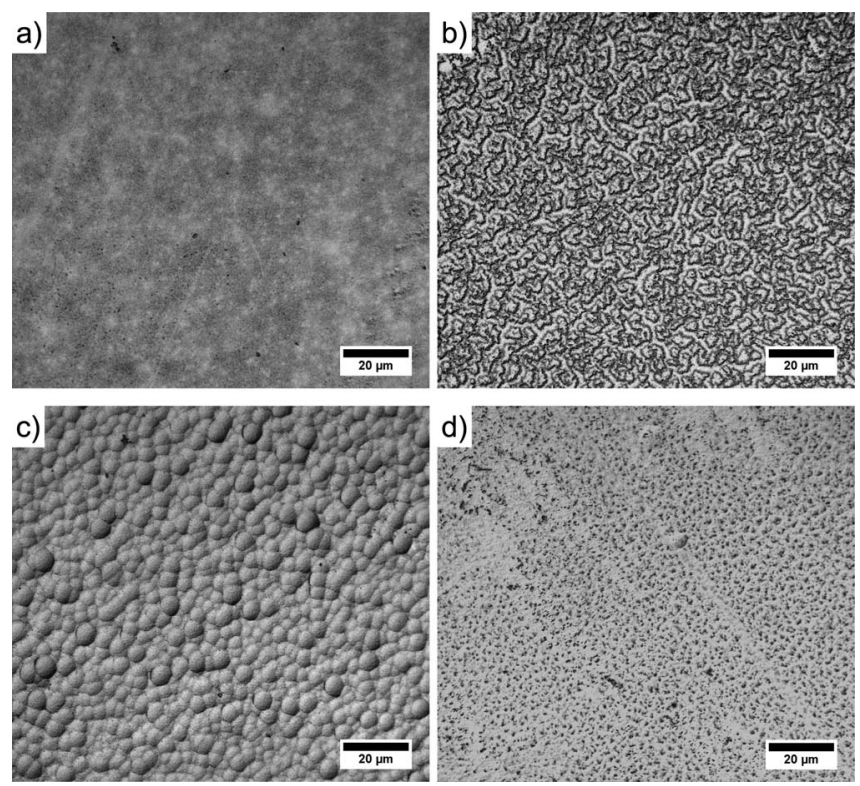

Figure 5. Surface morphology of B-doped Si anodes after discharge for $20 \mathrm{~h}$. a) $\langle 100\rangle$ oriented $\mathrm{Si}$, discharged at $0.1 \mathrm{~mA} / \mathrm{cm}^{2}$.b) $\langle 100\rangle$ oriented $\mathrm{Si}$, discharged at $0.3 \mathrm{~mA} / \mathrm{cm}^{2}$. c) $\langle 111\rangle$ oriented $\mathrm{Si}$, discharged at $0.1 \mathrm{~mA} / \mathrm{cm}^{2}$. d) $\langle 111\rangle$ oriented $\mathrm{Si}$, discharged at $0.3 \mathrm{~mA} / \mathrm{cm}^{2}$.
Along with higher current densities $\left(0.3 \mathrm{~mA} / \mathrm{cm}^{2}\right)$ on the surface of $\langle 100\rangle$ oriented B-doped Si anodes, island like structures, 5-10 $\mu \mathrm{m}$ in size, whereby the shape of the islands shows considerable tortuosity, are formed. These structures are separated by channels that are percolating within the surface plane (Fig. 5b). Island like structures are also present on the surface of anodes made from $\langle 111\rangle$ oriented B-doped Si when discharged at $0.3 \mathrm{~mA} / \mathrm{cm}^{2}$. Compared to the island on the $\langle 100\rangle$ surfaces, they do not show wound, tortuous shapes and are markedly smaller (Fig. 5d).

Corrosion studies from mass loss measurements.-Figure 6 represents the corrosion mass losses of As-, Sb-, and B-doped Si

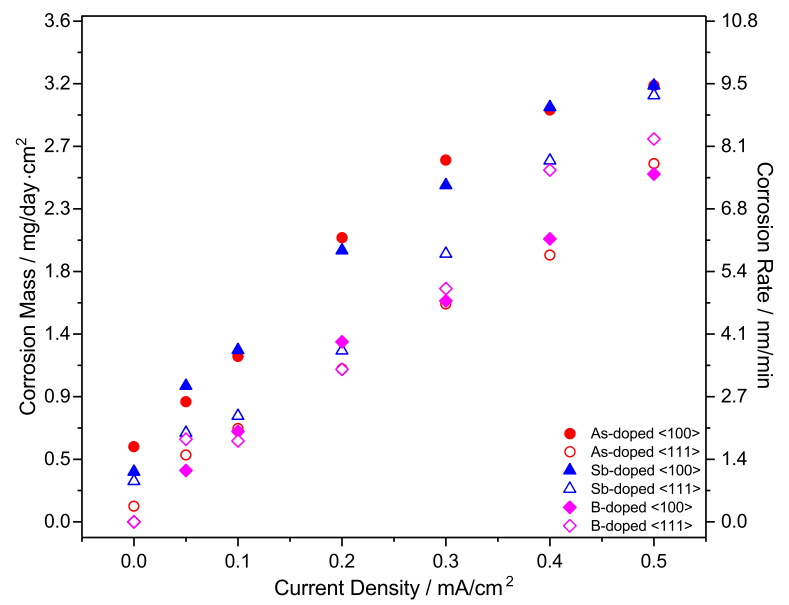

Figure 6. Corrosion mass loss after OCP and $20 \mathrm{~h}$ discharge experiments under current densities between $0.05 \mathrm{~mA} / \mathrm{cm}^{2}$ to $0.5 \mathrm{~mA} / \mathrm{cm}^{2}$ for As-, Sb- and $\mathrm{B}$-doped $\mathrm{Si}$ anodes. Corresponding corrosion rates are also shown on the right axis. 
anodes after $20 \mathrm{~h}$ discharge experiments at different current densities. The corrosion mass $\mathrm{m}_{\mathrm{c}}$ corresponds to the anode material consumed in electrochemical corrosion, chemical corrosion and, eventually, other possible side reactions if present. For both, $\mathrm{n}$ - and p-type of $\mathrm{Si}$ anode materials, the corrosion mass losses increase with the current density. The increase is almost linear for $\mathrm{n}$-type $\mathrm{Si}$ anodes within a wide range of current densities (up to $0.3 \mathrm{~mA} / \mathrm{cm}^{2}$ ). Moreover, in the same current range, $\mathrm{m}_{\mathrm{c}}$ is significantly lower $(\sim 20-30 \%)$ for $\mathrm{n}$-type $\mathrm{Si}$ anodes with $\langle 111\rangle$ orientation than for those with $\langle 100\rangle$ orientation. However, the difference almost diminishes along with high current densities (above $0.4 \mathrm{~mA} / \mathrm{cm}^{2}$ ). This trend is more pronounced for the Sb-doped $\mathrm{Si}$ anodes than for the As-doped.

Corrosion mass analysis revealed similar trends for $\mathrm{p}$-type $\mathrm{Si}$ anodes to n-type Si anodes (Fig. 6). The corrosion mass losses were increased with higher current densities. However, B-doped Si anodes showed significantly lower corrosion mass losses compared to n-type $\langle 100\rangle \mathrm{Si}$ anodes. Furthermore, up to $0.4 \mathrm{~mA} / \mathrm{cm}^{2}$, the corrosion mass losses were similar for both orientations. Higher current densities enhanced the corrosion mass losses of $\langle 111\rangle$ orientation in comparison to $\langle 100\rangle$, although the discharge profiles were quantitatively the same (Fig. 1). In this study as different than conventional solutions in which the $\langle 100\rangle$ planes corrode faster than $\langle 111\rangle$ planes, ${ }^{16}$ we observed for the first time higher corrosion rates for $\langle 111\rangle$ orientations than $\langle 100\rangle$ oriented Si electrodes when discharged at high current densities $(>0.3$ $\mathrm{mA} / \mathrm{cm}^{2}$ ). On the other hand, no mass change was observed for Bdoped $\mathrm{Si}$ anodes after OCP period. This could originate from very slow reaction kinetics at OCP resulting from electrochemical and other side reactions.

Potentiodynamic polarization experiments.-According to the potentiodynamic polarization experiments, the OCP for all n-type $\mathrm{Si}$ wafers are very similar ranging from $-1.35 \mathrm{~V}$ to $-1.45 \mathrm{~V}$ vs. $\mathrm{Cp}_{2} \mathrm{Fe} / \mathrm{Cp}_{2} \mathrm{Fe}^{+}$based gel electrode (Fig. 7a). The OCP for the half cells with B-doped Si wafers are substantially less negative and more sensitive to crystal orientation. Anodes from B-doped Si with $\langle 111\rangle$ orientation provide an OCP at $-1.18 \mathrm{~V}$ whereas the OCP for those with $\langle 100\rangle$ orientation is $-1.02 \mathrm{~V}$. Differences between $\mathrm{n}$ - and $\mathrm{p}$-type $\mathrm{Si}$ anodes are also indicated with respect to their potentials at different current densities when the electrodes are scanned in the anodic direction. While for the p-type anodes a potential drop is initiated along with current densities of $10^{-3} \mathrm{~mA} / \mathrm{cm}^{2}$, almost more than one order of magnitude higher current densities can be applied for the n-type $\mathrm{Si}$ anodes until the potential starts to decrease. However, within an intermediate current density regime of $0.05 \mathrm{~mA} / \mathrm{cm}^{2}$ to $1 \mathrm{~mA} / \mathrm{cm}^{2}$, the decrease of the potential for the B-doped $\mathrm{Si}$ anodes with increasing current density is quite moderate. In contrast to that, there is a sharp decrease on the potentials for the As- and Sb-doped Si anodes in the range of $0.1 \mathrm{~mA} / \mathrm{cm}^{2}$. When the current density was increased from $0.05 \mathrm{~mA} / \mathrm{cm}^{2}$ to $0.3 \mathrm{~mA} / \mathrm{cm}^{2}$, the potential drops were found to be 0.3 $\mathrm{V}$ and $0.5 \mathrm{~V}$ for As- and Sb-doped Si wafers, respectively.

Toward current densities higher than $0.4 \mathrm{~mA} / \mathrm{cm}^{2}$, the differences in potentials between the B-doped and As-doped anodes almost vanish $(-0.76 \mathrm{~V}$ vs. $-0.86 \mathrm{~V})$ in comparison to low current densities, while for the $\mathrm{Sb}$-doped $\mathrm{Si}$ anodes the potentials were found to be even slightly below B-doped Si anodes. A summary of the discharge potentials under different current densities up to $0.5 \mathrm{~mA} / \mathrm{cm}^{2}$ is given in Figure 7b.

Corrosion rates derived from the potentiodynamic polarization curves are ranging from 0.01 to $0.03 \mathrm{~nm} / \mathrm{min}$ (Table I). In agreement with a previous investigation, ${ }^{11}$ the B-doped materials show lower electrochemical corrosion rates than the As- and Sb-doped Si anodes. Overall the results of both experimental sets indicate a very low level of electrochemical corrosion. Differences between the results from the actual study in comparison to literature ${ }^{11}$ emerge, however, from slightly different specifications of the Si-wafers, different batches of the EMIm $(\mathrm{HF})_{2.3} \mathrm{~F}$ electrolyte and the use of Pt-reference electrode in the previous vs. gelled electrode in the present polarization experiments.
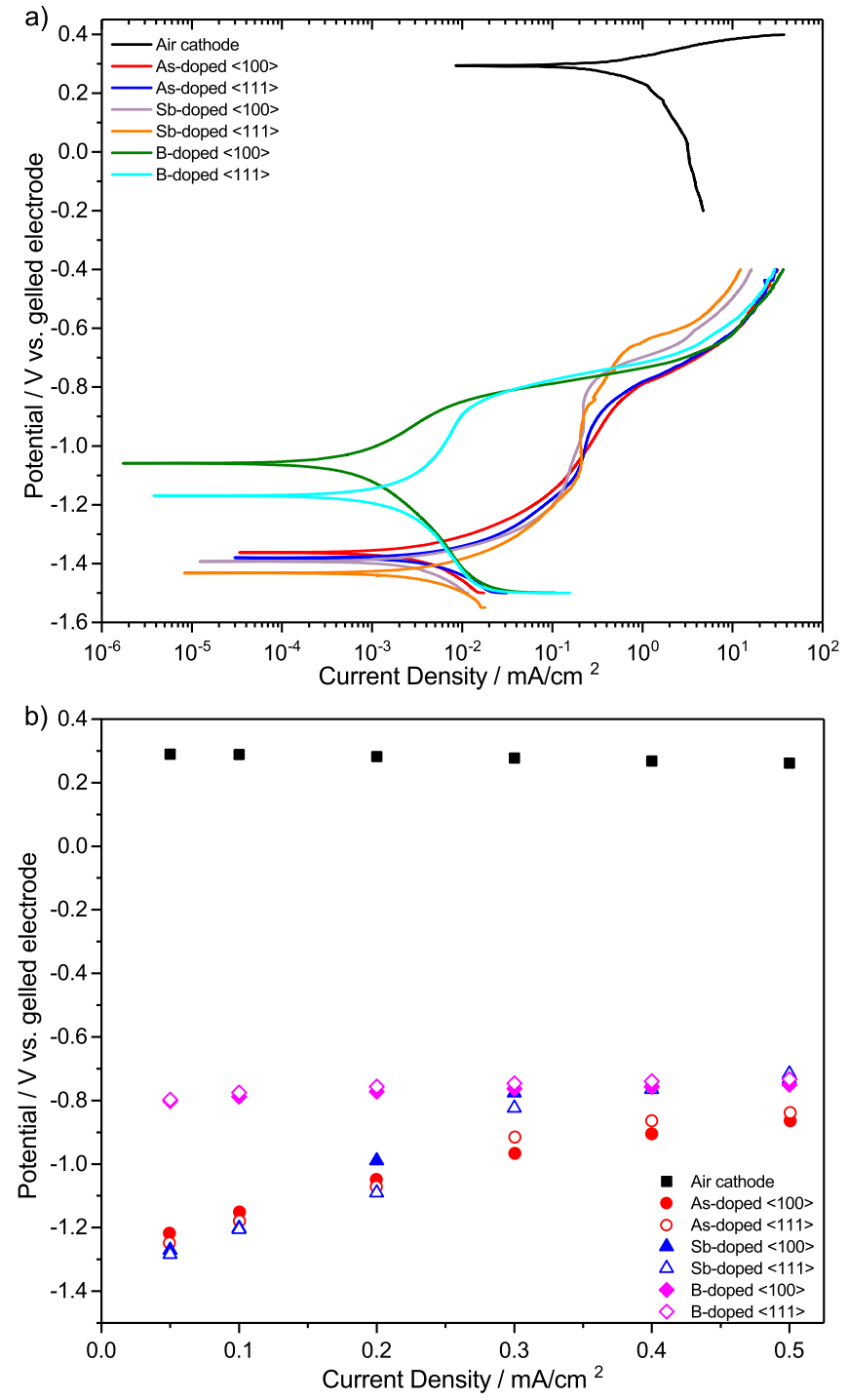

Figure 7. a) Polarization voltammograms of cathode and $\langle 100\rangle$ and $\langle 111\rangle$ oriented As-, Sb- and B-doped $\mathrm{Si}$ anodes in $\mathrm{EMIm}(\mathrm{HF})_{2.3} \mathrm{~F}$ electrolyte measured at a scan rate of $1 \mathrm{mV} / \mathrm{s}$. b) Potentials obtained from the polarization curves of anodes and cathode at specific current densities.

\section{Discussion}

The role of polarization and discharge experiments for materials screening.-Potentiodynamic polarization is a powerful electrochemical technique which provides important parameters such as kinetics of the reactions, corrosion values, and potential vs. current

\section{Table I. Comparison of the corrosion rates obtained from potentiodynamic polarization curves and the discharge experiments at $0.05 \mathrm{~mA} / \mathrm{cm}^{2}$.}

\begin{tabular}{cccc} 
Si wafer type & $\begin{array}{c}\text { Cohn et al. }{ }^{11} \\
\text { Polarization } \\
\mathrm{nm} / \mathrm{min}\end{array}$ & $\begin{array}{c}\text { Present data } \\
\text { Polarization } \\
\mathrm{nm} / \mathrm{min}\end{array}$ & $\begin{array}{c}\text { Present data Mass change } \\
\left(\text { at } 0.05 \mathrm{~mA} / \mathrm{cm}^{2}\right) \\
\mathrm{nm} / \mathrm{min}\end{array}$ \\
\hline $\mathrm{As}\langle 100\rangle$ & 0.08 & 0.02 & 2.58 \\
$\mathrm{As}\langle 111\rangle$ & 0.08 & 0.03 & 1.44 \\
$\mathrm{Sb}\langle 100\rangle$ & 0.07 & 0.02 & 2.92 \\
$\mathrm{Sb}\langle 111\rangle$ & - & 0.03 & 1.91 \\
$\mathrm{~B}\langle 100\rangle$ & 0.01 & $<0.01$ & 1.10 \\
$\mathrm{~B}\langle 111\rangle$ & $<0.01$ & 0.01 & 1.78
\end{tabular}



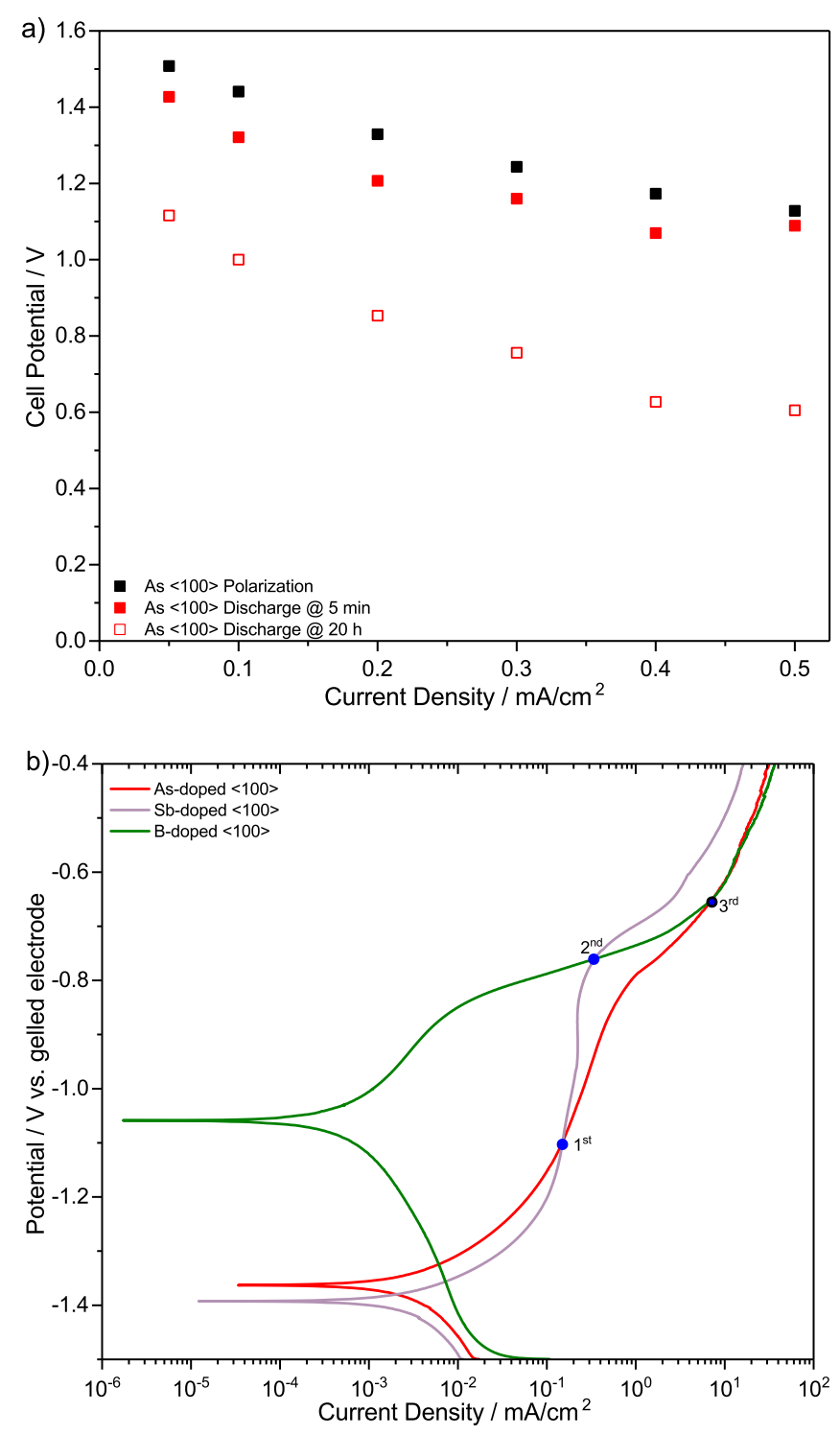

Figure 8. a) Comparison of the cell potentials obtained from polarization curves and $20 \mathrm{~h}$ discharge experiments for $\langle 100\rangle$ oriented As-doped Si anodes. The potentials were taken after 5 minutes and 20 hours discharge times from Figure 1a. b) Critical current densities for $\langle 100\rangle$ oriented As-, Sb-, and B-doped $\mathrm{Si}$ anodes where the individual potentials intersect each other.

characteristics according to Butler-Volmer equation and mixed potential theory. ${ }^{17-19}$ However, the polarization results with respect to the potential characteristics might be challenging to conform to long run discharge experiments. Indeed, the former should be the first step of the investigation for a new system in order to address an appropriate current range; otherwise, the discharge experiments may not be feasible. Therefore, the discussion will be focused on which information could be obtained from potentiodynamic polarization and how it can be interpreted for the discharge performance, and what additional information (i.e. microstructure, corrosion etc.) is available from discharge experiments with respect to the operation of $\mathrm{Si}$-air batteries with $\operatorname{EMIm}(\mathrm{HF})_{2.3} \mathrm{~F}$ electrolyte.

Potential vs. discharge current characteristics. - The cell potentials measured in the $20 \mathrm{~h}$ discharge experiments are plotted against the potentials calculated from the difference of the cathode and the $\langle 100\rangle$ oriented As-doped Si anode on the polarization curves as shown in Figure 8a. The cell potentials from discharge experiments were obtained after 5 minutes and 20 hours from Figure 1a. The level of the potentials after 5 minutes discharge is by 50 to $100 \mathrm{mV}$ lower than the potentials measured in the polarization experiment. The difference increases significantly along with longer discharge times; the potentials at the end of discharge experiments are by $400 \mathrm{mV}$ less for the low current densities (up to $0.1 \mathrm{~mA} / \mathrm{cm}^{2}$ ) and by $500 \mathrm{mV}$ less for the higher current densities. Since the potentiodynamic polarization is a transient method, the comparison with the constant current discharge experiments results in lower potentials especially in the longer runs. Additionally, polarization effects, modification of the anode surface and electrolyte due to the electrochemical and corrosion reactions contribute on the increased differences along with the discharge durations. Therefore, the potentials were remarkably similar for the comparison only within the 5 minutes of discharge time. Nonetheless, potentiodynamic polarization experiments could still provide reliable potentials for the systems where the surface and electrolyte modifications are negligible.

With respect to a ranking of the anode materials within a more general range of current densities, the "critical current densities" i.e. the current densities at which there are intersections of the individual potential curves have to be considered. The intersections between the polarization curves for the $\langle 100\rangle$ oriented As-, Sb-, and B-doped $\mathrm{Si}$ anodes are shown in Figure $8 \mathrm{~b}$. The discharge potentials at the end of $20 \mathrm{~h}$ discharge experiments are given in Figure 9a. The cell potentials for As- and Sb-doped anodes are almost equal at 0.05 and $0.1 \mathrm{~mA} / \mathrm{cm}^{2}$ while the intersection point $\left(1^{\text {st }}\right.$ point on Fig. $\left.8 \mathrm{~b}\right)$ according to the polarization experiments is at $0.15 \mathrm{~mA} / \mathrm{cm}^{2}$. The minimum current at which the potential for the As-doped $\mathrm{Si}$ anode exceeds the potential of the Sb-doped $\mathrm{Si}$ is shifted only slightly to higher current densities. On the other hand, the intersection of the polarization curves for Sb- vs. B-doped $\mathrm{Si}$ anodes is at $0.34 \mathrm{~mA} / \mathrm{cm}^{2}$ whereas the discharge experiments assign a break-even potential at $0.4 \mathrm{~mA} / \mathrm{cm}^{2}$. At sufficiently high current densities $\left(7 \mathrm{~mA} / \mathrm{cm}^{2}\right)$, the polarization curves for As- and B-doped Si also intersect ( $3^{\text {rd }}$ point).

For the present materials screening, the range for the current densities was selected according to a potential range higher than $0.4 \mathrm{~V}$. Within this range, although a comparison of the cell potentials derived from polarization and intermediate discharge experiments showed quantitatively similar values at the beginning of the discharge, they deviated significantly through the end of the discharge experiments. Nevertheless, qualitatively a good agreement between the two experiments is achieved with respect to the evaluation of the anode materials.

Surface microstructure.-Discharge experiments allow for the analysis of the surface microstructure after operation of the battery under constant conditions. Considering the surface morphologies one has to be aware that they describe the state at one point of time. Therefore, the results presented here demonstrate the different surface morphology depending on the Si wafer type after $20 \mathrm{~h}$ discharge in $\mathrm{EMIm}(\mathrm{HF})_{2.3} \mathrm{~F}$. However, a complete monitoring of the time development of the surface morphologies during the OCP and discharge period is out of the scope of this study.

Although significant differences in the surface microstructures were detected for $\langle 100\rangle$ vs. $\langle 111\rangle$ oriented Si anodes for all types of dopants, the discharge characteristics are very similar. Nonetheless, analysis of the surface microstructure in more detail was motivated by i) the identification of whether reaction products are deposited on the anode surfaces and, ii) gaining insights into the mechanisms of discharge as a function of surface orientation. Hence; the surface microstructure analysis plays a very important role for the evaluation of mass losses with respect to corrosion and provides the precondition for a correct analysis of the corrosion rates.

The surface microstructure was analyzed across various length scales by LSM, optical microscopy and AFM. For n-doped $\langle 100\rangle$ orientations no specific structure except for small pits are found. Similar pit formations were also observed by Raz et al. before the porous layer growth by application of relatively high potential or current densities. ${ }^{20,21}$ In this study, we report pillar formations which emerge from similar mechanisms as reported by Raz et al. but at much smaller scale due to application of low current densities. ${ }^{20,21}$ In comparison 

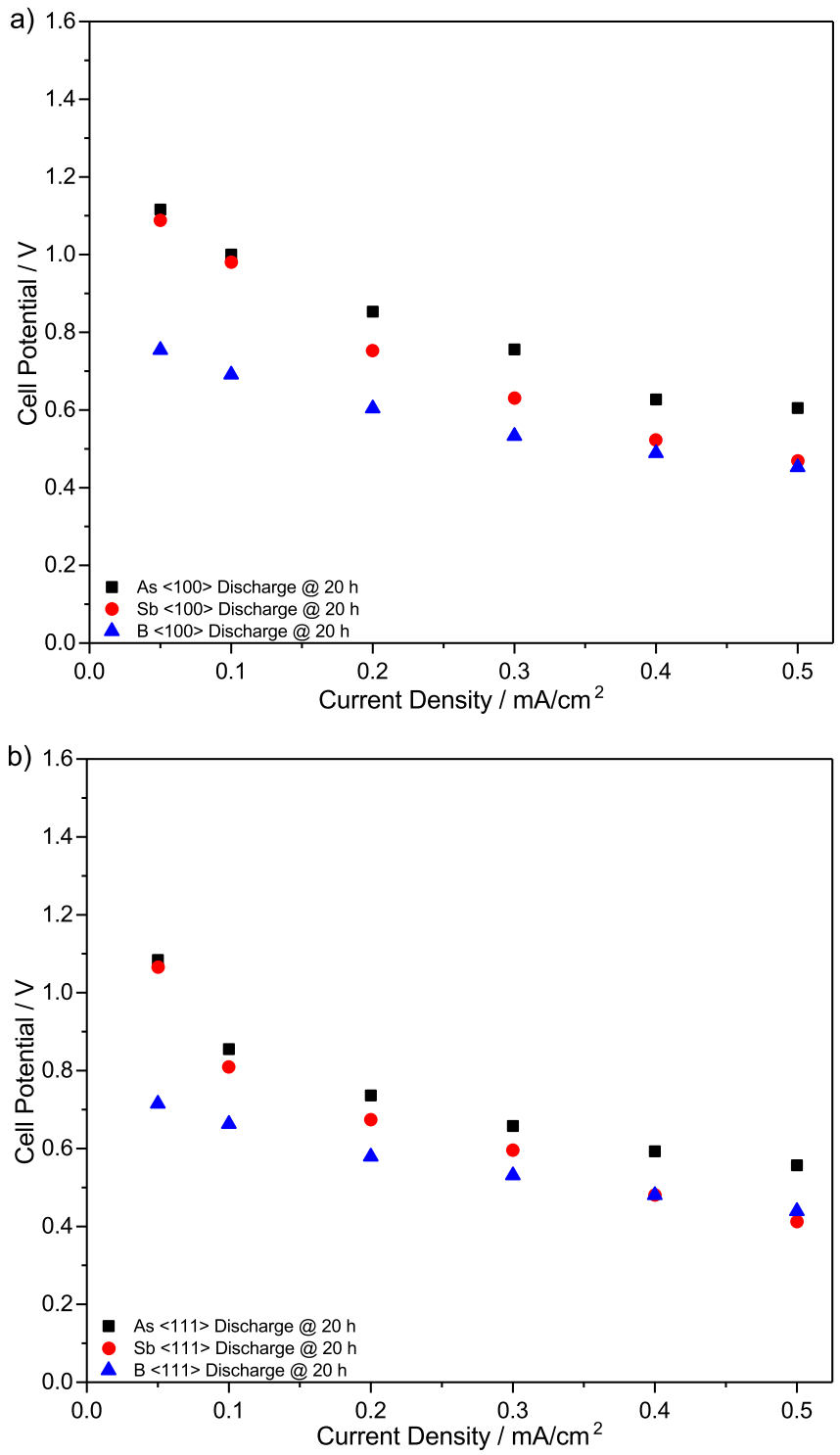

Figure 9. Discharge potentials at the end of $20 \mathrm{~h}$ runs in $\mathrm{Si}$-air full cells with $\operatorname{EMIm}(\mathrm{HF})_{2.3} \mathrm{~F}$ electrolyte under discharge current densities from 0.05 $\mathrm{mA} / \mathrm{cm}^{2}$ to $0.5 \mathrm{~mA} / \mathrm{cm}^{2}$ for a) $\langle 100\rangle$ oriented As-, Sb-, and B-doped $\mathrm{Si}, \mathrm{b}$ ) $\langle 111\rangle$ oriented As-, Sb-, and B-doped Si anodes.

to fresh Si wafer surfaces (Fig. S2), it is clear that the pits and the other surface structures were mainly formed during the experiments due to possible surface defects ${ }^{22}$ and high Si dissolution rates at local spots. ${ }^{20,21}$ In the case of $n$-doped $\langle 111\rangle$ orientations characteristic polygon like structures are observed. As the domain walls consists of numerous pillars, especially on n-doped $\langle 111\rangle$ surfaces, the calculation of the exact corrosion rate critically depends on the verification of the nature of material. The phase signal obtained by AFM strongly indicates that all material is rather identical and no deposits are present. This conclusion is supported by the observation that in all cases the height differences after the discharge of the battery are in the nanometer range. Such small variations are marginal compared to the overall corrosion process that etched away up to $14 \mu \mathrm{m}$ in the case of discharge with $0.5 \mathrm{~mA} / \mathrm{cm}^{2}$. Furthermore, differences in the crystal orientations result in the variations of the surface microstructures but mostly leave the electrochemical reactions unaffected whereas the corrosion mass losses are also influenced.

Corrosion.-Electrochemical corrosion as identified from the polarization experiments is one of the mechanism that contributes to the anode mass loss during the operation of Si-air cells with $\mathrm{EMIm}(\mathrm{HF})_{2.3} \mathrm{~F}$ electrolyte. If there are other side reactions, which are chemical in nature, polarization experiments would underestimate the calculated corrosion parameters. Therefore, pointing to the objective to quantify the mass losses of the anode which are not converted into electrical energy, other side reactions have to be taken into account beside the electrochemical corrosion. Especially for $\mathrm{Si}$-air battery with $\mathrm{EMIm}(\mathrm{HF})_{2.3} \mathrm{~F}$ electrolyte, the contribution of the electrochemical corrosion to the total corroded mass loss is very small; the difference is up to two orders of magnitude (Table I). This difference could originate from three reasons: first, the selection and analysis of the Tafel regime from the polarization curves could result in some errors. However, the calculated corrosion parameters are quite close to literature, ${ }^{11}$ and the error cannot be up to two orders of magnitude. Second, the conversion of the corrosion current to mass loss or opposite assumes a four electron process. If there are other processes with two electrons, this might contribute to the difference. Third and more severe, the polarization results do not take the chemical corrosion into account, although it is the main origin of the corroded mass loss. Due to the relatively short run time of polarization experiments, the mass losses are almost negligible and therefore, the chemically corroded mass could not be measured by this method.

According to the parameters (Table I) obtained from the polarization curves in Figure 7, B-doped materials show lower electrochemical corrosion rates than the As- and Sb-doped Si anodes. At the first sight, relatively high corrosion potentials can be observed for n-type electrodes between 1.35 to $1.45 \mathrm{~V}$, while at least $0.17 \mathrm{~V}$ lower corrosion potentials are obtained for p-type Si electrodes. Additionally, the curves are shifted slightly to higher current densities for n-type Si electrodes. Consequently, these results support that p-type Si electrodes show more "passive" behavior than n-type Si electrodes in $\operatorname{EMIm}(\mathrm{HF})_{2.3} \mathrm{~F}$ electrolyte. The window of "passivity" for p-type electrodes is between $200-250 \mathrm{mV}$ vs. corrosion potential. Potentials above this range might result in formation of semi-permeable surface layers composed of possibly $\mathrm{Si}-\mathrm{F}-\mathrm{B}$ elements which still allow ion transfer. Accordingly, discharge could continue but at lower potentials due to resistive behavior of the surface layer. For the n-type Si electrodes, similar behavior can be observed at much higher discharge current densities.

The origin of this behavior can originate from the high dopant concentrations in the Si electrodes that we employed in this study. Similar trends were also observed for heavily-doped Si electrodes in alkaline media. ${ }^{16}$ In the case of B-dopant, the etch rate reduction up to three orders of magnitude could be obtained for Si electrodes with increasing the boron concentration from $10^{19} / \mathrm{cm}^{3}$ to $10^{20} / \mathrm{cm}^{3}{ }^{3}{ }^{16,23}$ Although the etch rate reduction for highly doped $\mathrm{Si}$ electrodes in strongly acidic solutions was not observed, ${ }^{16,24}$ we assume that $\operatorname{EMIm}(\mathrm{HF})_{2.3} \mathrm{~F}$ ionic liquid shows similar behavior to alkaline media. Moreover, the chemical and electrochemical behavior of heavily-doped Si electrodes in $\mathrm{EMIm}(\mathrm{HF})_{2.3} \mathrm{~F}$ ionic liquid are still unknown and more investigations are needed to understand the influence of dopant concentrations and crystal orientations of Si electrodes. In this regard, this study shows the first insights which could pioneer further investigations.

Amounting up to $3.2 \mathrm{mg} /\left(\mathrm{day} \cdot \mathrm{cm}^{2}\right)$ anode mass losses during the discharge, the corrosion mass losses become an important issue for materials selection. Therefore, for an evaluation of the materials with respect to corrosion and anode mass conversion efficiency, discharge experiments with concomitant mass change analysis is required. Otherwise, basing only on the corrosion rates determined from polarization experiments would underestimate the results up to two orders of magnitude for $\mathrm{Si}$-air batteries with $\mathrm{EMIm}(\mathrm{HF})_{2.3} \mathrm{~F}$ electrolyte.

Evaluation of As-, Sb- and B-doped Si anodes.-Summary of performance.-The discharge potentials of $\mathrm{Si}$-air cells with different type of Si anodes depending on current densities are summarized in Figure 9. The data for the potentials refer to the end of discharge experiments. While there is pronounced influence from the type of dopant in the Si anodes, especially n- vs. p-type, the cell potentials for $\mathrm{Si}$ anodes containing the same dopants with different orientation 


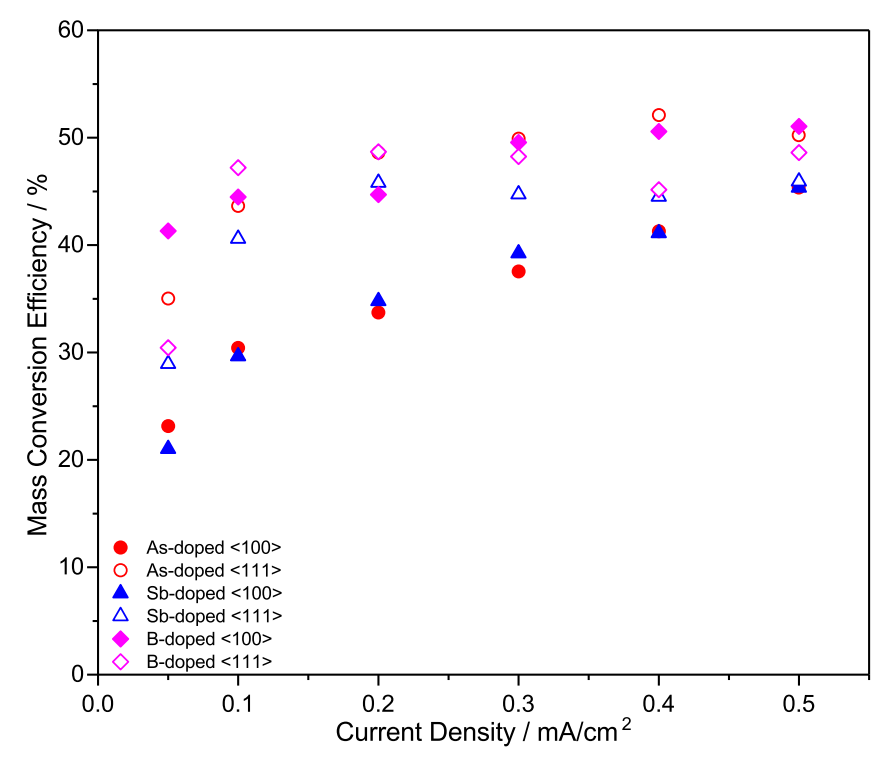

Figure 10. The influence of the discharge current densities on the anode mass conversion efficiencies for $\mathrm{Si}$-air cells. The values were calculated after the 20 $\mathrm{h}$ discharge experiments shown in Figure 1.

$(\langle 100\rangle$ vs. $\langle 111\rangle)$ are quite similar. The highest discharge potentials were realized - independent of the current density - in the cells with As-doped Si anodes. Cells with anodes prepared from B-doped Si show lower discharge potentials, whereby the differences to the cells with As-doped Si anodes are most pronounced at low current densities and decrease at higher current densities. The discharge potentials of cells with Sb-doped $\mathrm{Si}$ anodes are close to those of cells with As-doped anodes with same orientations at low current densities, whereas they are similar to cells with B-doped $\mathrm{Si}$ anodes at high current densities. Therefore, the performance of Si-air cells for $20 \mathrm{~h}$ discharge experiments is dominated by the dopant type of the $\mathrm{Si}$ anode, whereby the potentials for As-, Sb-, and B-doped Si anodes show quantitatively different dependence on current density. An assessment on ranking of the $\mathrm{Si}$ anodes with respect to the discharge potentials could be split considering high and low discharge current densities. For the low current densities $\left(0.05 \mathrm{~mA} / \mathrm{cm}^{2}\right)$

$$
\mathrm{As}_{100}>\mathrm{As}_{111} \approx \mathrm{Sb}_{100}>\mathrm{Sb}_{111} \gg \mathrm{B}_{100}>\mathrm{B}_{111},
$$

while for high current densities $\left(0.5 \mathrm{~mA} / \mathrm{cm}^{2}\right)$ the ranking is

$$
\mathrm{As}_{100}>\mathrm{As}_{111} \gg \mathrm{Sb}_{100}>\mathrm{B}_{100}>\mathrm{B}_{111}>\mathrm{Sb}_{111}
$$

where the symbols $\gg,>$, and $\approx$ are denoted for at least $\Delta \mathrm{E}=0.1 \mathrm{~V}$, $0.03 \mathrm{~V}$, and $0.01 \mathrm{~V}$, respectively.

Corrosion, anode mass conversion efficiency and specific energy.The corrosion mass is a factor which influences the anode mass conversion efficiency according to Eq. 4 . Analysis of anode mass changes during discharge and anode mass conversion efficiencies have to be considered as crucial factors for materials screening in $\mathrm{Si}$-air batteries with $\mathrm{EMIm}(\mathrm{HF})_{2.3} \mathrm{~F}$ electrolyte. Thus, the evaluated anodic mass conversion efficiencies at different discharge current densities are shown in Figure 10. Although quiet similar discharge characteristics were obtained for all n-type $\mathrm{Si}$ anodes, the mass conversion efficiencies reveal some distinct differences between $\langle 100\rangle$ and $\langle 111\rangle$ oriented anodes at low currents. This difference vanishes along with increasing the discharge current densities up to $0.5 \mathrm{~mA} / \mathrm{cm}^{2}$. On the other hand, despite relatively lower discharge potentials of $\mathrm{B}$-doped $\mathrm{Si}$ anodes, the mass conversion efficiencies for both orientations are mostly in between 45 to 50\%; higher than almost all n-type anodes. The overall ranking of the $\mathrm{Si}$ anodes in terms of anodic mass conversion efficiencies $(\eta)$ is given as

$$
\mathrm{B}_{100} \approx \mathrm{B}_{111} \approx \mathrm{As}_{111}>\mathrm{Sb}_{111} \gg \mathrm{Sb}_{100} \approx \mathrm{As}_{100}
$$
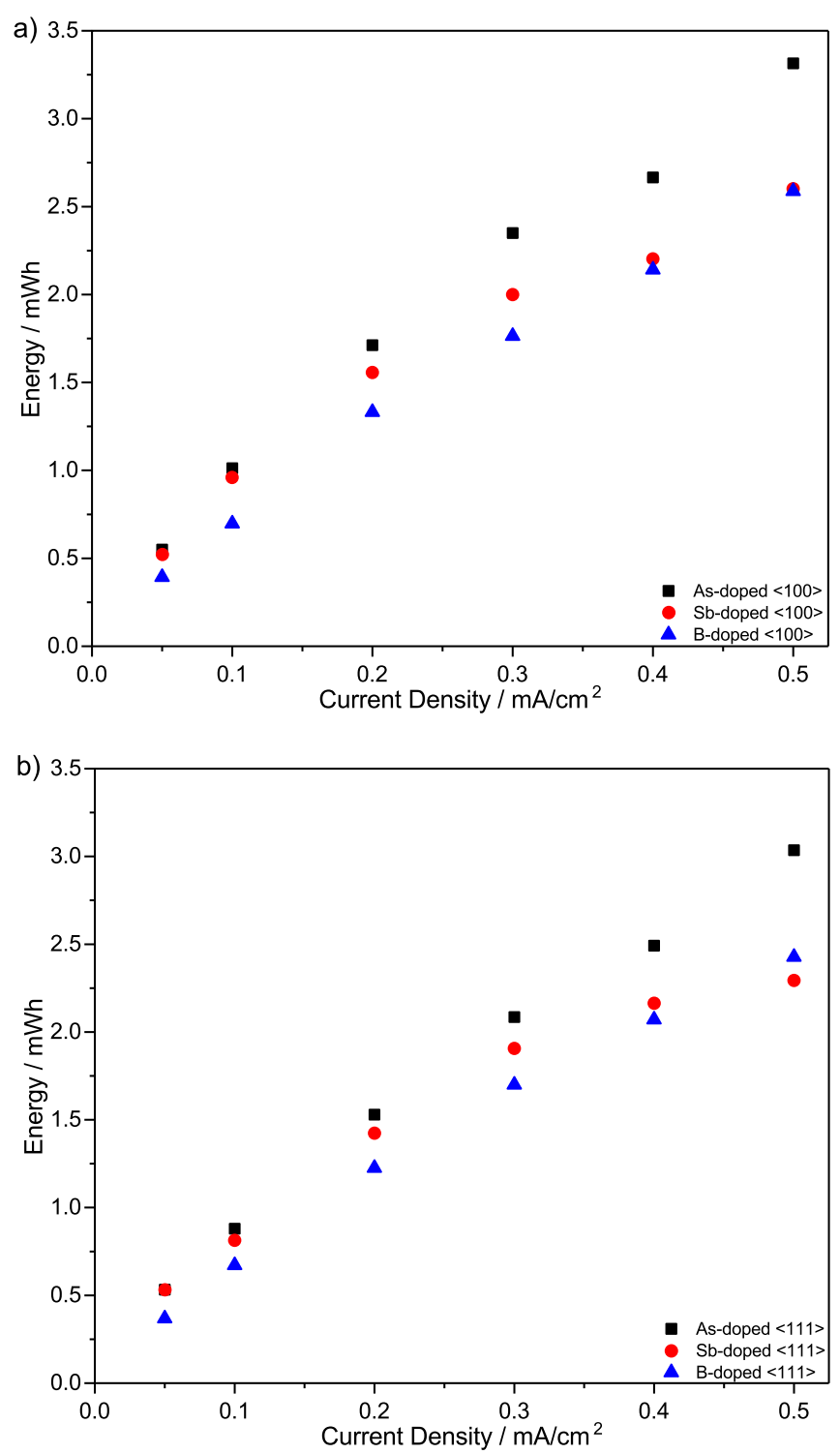

Figure 11. Specific energy after $20 \mathrm{~h}$ operation in Si-air full cells with $\operatorname{EMIm}(\mathrm{HF})_{2.3} \mathrm{~F}$ electrolyte depending on anode type and current density. a) $\mathrm{As}\langle 100\rangle, \mathrm{Sb}\langle 100\rangle$ and $\mathrm{B}\langle 100\rangle \mathrm{Si}$ anodes b) $\mathrm{As}\langle 111\rangle, \mathrm{Sb}\langle 111\rangle$, and $\mathrm{B}\langle 111\rangle \mathrm{Si}$ anodes.

where the symbols $\gg,>$, and $\approx$ are denoted for at least $\Delta \eta=5 \%$, $3 \%$, and $1 \%$, respectively.

The energies of discharged $\mathrm{Si}$-air cells with different $\mathrm{Si}$ anodes are summarized in Figure 11. Corresponding to the discharge profiles for $20 \mathrm{~h}$, the highest discharge energies are delivered by the As-doped and lowest by the B-doped Si anodes. The Sb-doped anodes provided similar discharge energies to As-doped anodes at low current densities, whereas they approach the values of the B-doped anodes under high current densities. From a merely energetic point of view these results suggest to use high discharge current densities to deliver increased discharge energies. However, practical aspects support the limitation of the current densities to a range where the energy is provided at a potential of more than at least $0.4 \mathrm{~V}$.

The specific energies $\mathrm{w}_{\mathrm{cam}}$ for the $\mathrm{n}$ - and $\mathrm{p}$-type $\mathrm{Si}$ anodes related to the total anode mass consumed during cell operation are represented in Figure 12. It is important to note that only the total mass loss $\left(\mathrm{m}_{\mathrm{t}}\right.$ $=m_{d}+m_{c}$ ) is considered for the evaluation instead of the whole Si piece which is $11 \times 11 \mathrm{~mm}$ in size. The specific energies related to the consumed anode mass $\mathrm{w}_{\mathrm{cam}}$ are in the range between 970 and 

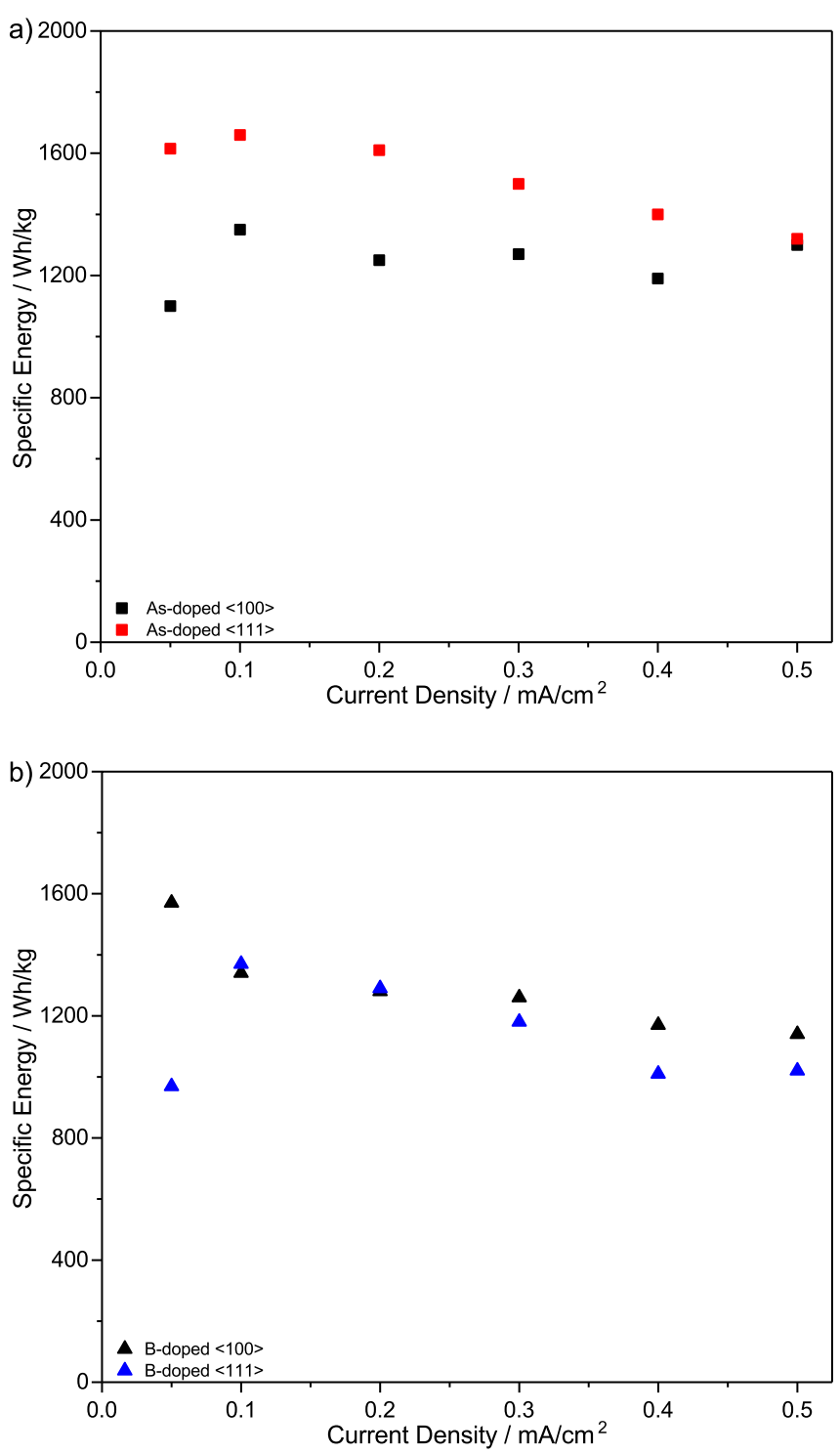

Figure 12. Discharged specific energies per anode mass loss during $20 \mathrm{~h}$ operation in Si-air full cells with $\mathrm{EMIm}(\mathrm{HF})_{2.3} \mathrm{~F}$ electrolyte depending on anode type and current density. a) As $\langle 100\rangle$ vs. As $\langle 111\rangle$ Si anodes, b) B $\langle 100\rangle$ vs. $\mathrm{B}\langle 111\rangle \mathrm{Si}$ anodes.

$1660 \mathrm{Wh} / \mathrm{kg}$, depending on the anode type and current densities. The highest $\mathrm{w}_{\mathrm{cam}}$ is realized for $\langle 111\rangle$ oriented As-doped Si anodes under current densities of 0.05 and $0.1 \mathrm{~mA} / \mathrm{cm}^{2}$, for which it amounts up to 1615 and $1660 \mathrm{Wh} / \mathrm{kg}$, respectively. Higher discharge current densities decrease the $\mathrm{w}_{\text {cam }}$ slightly; $1300 \mathrm{Wh} / \mathrm{kg}$ is realized at $0.5 \mathrm{~mA} / \mathrm{cm}^{2}$. In contrast to that, for As-doped Si-anodes with $\langle 100\rangle$ orientation $\mathrm{w}_{\text {cam }}$ remains almost constant at $1300 \mathrm{Wh} / \mathrm{kg}$ in the current range between 0.1 and $0.5 \mathrm{~mA} / \mathrm{cm}^{2}$. The Sb-doped $\mathrm{Si}$ anodes show lower specific energies (Fig. S3) than the As-doped Si anodes especially within the comparison of same orientation. For example, $\langle 111\rangle$ oriented Sbdoped Si anodes provide 200 and $409 \mathrm{Wh} / \mathrm{kg}$ lower specific energies for the discharge current densities of 0.2 and $0.5 \mathrm{~mA} / \mathrm{cm}^{2}$, respectively. Furthermore, employing B-doped $\mathrm{Si}$ as anode lowers the $\mathrm{w}_{\text {cam }}$ in comparison to the As-doped electrodes, while resulting in similar $\mathrm{w}_{\text {cam }}$ to Sb-doped Si. Overall, $\langle 111\rangle$ orientation show higher specific energies for $\mathrm{n}$-type electrode, whereas $\langle 100\rangle$ is slightly higher for $\mathrm{p}$ type electrodes. Therefore, in terms of overall specific energies $w_{c a m}$ the $\mathrm{Si}$ anodes are ranked as

$$
\mathrm{As}_{111} \gg \mathrm{As}_{100}>\mathrm{Sb}_{111}>\mathrm{B}_{100}>\mathrm{B}_{111} \approx \mathrm{Sb}_{100} .
$$

where the symbols $\gg,>$, and $\approx$ are denoted for at least $\Delta \mathrm{w}_{\mathrm{cam}}=200$ $\mathrm{Wh} / \mathrm{kg}, 100 \mathrm{Wh} / \mathrm{kg}$, and $50 \mathrm{Wh} / \mathrm{kg}$, respectively.

In summary, according to discharge performance, anode mass conversion efficiencies, and specific energies, the $\langle 111\rangle$ oriented Asdoped $\mathrm{Si}$ anodes are considered to be the best choice as an anode material in $\mathrm{Si}$-air batteries with $\operatorname{EMIm}(\mathrm{HF})_{2.3} \mathrm{~F}$ electrolyte. In the present state of development of such batteries, investigating and overcoming the discharge limitations and accordingly, designing a battery suitable for full consumption of the anode material has remained as a major concern.

\section{Conclusions}

Anodes prepared from $\langle 100\rangle$ and $\langle 111\rangle$ oriented Si wafers doped with $\mathrm{As}, \mathrm{Sb}$ or $\mathrm{B}$ have been investigated with respect to their performance and efficiency in discharge of $\mathrm{Si}$-air full cells using $\mathrm{EMIm}(\mathrm{HF})_{2.3} \mathrm{~F}$ electrolyte. Discharge potentials under current densities in the range between 0.05 and $0.5 \mathrm{~mA} / \mathrm{cm}^{2}$ were evaluated after $20 \mathrm{~h}$ discharge experiments for each anode material. As-doped Si anodes showed the highest potentials almost independent of the crystal orientation. B-doped $\mathrm{Si}$ anodes provided lower OCP and discharge potentials than As-, and Sb-doped $\mathrm{Si}$ anodes. The potentials of the cells with $\mathrm{Sb}$-doped $\mathrm{Si}$ anodes under OCP and at low current densities were close to those of the As-doped, whereas at high current densities they approached the potentials of the cells with B-doped Si anodes. Marked differences in surface morphologies of the wafers after $20 \mathrm{~h}$ discharge were found. The effect of surface microstructures on the potentials is however much less than the influence from dopant type of $\mathrm{Si}$ anodes.

Furthermore, experiments were undertaken to determine the corrosion rates from polarization measurements. The electrochemical corrosion rates calculated from the polarization experiments are in agreement to those found in the literature. Corrosion rates were also determined from mass losses of the anode materials. In comparison to the electrochemical corrosion rates determined from polarization curves, the corrosion rates from mass losses are higher by almost two orders of magnitude. While polarization measurements may be suitable as a base for an estimation of the electrochemical corrosion, the major part of mass losses at the anode seems to emerge from other reactions and mechanisms. Therefore, an overall evaluation of the anode mass conversion efficiency of $\mathrm{Si}$-air batteries requires also consideration of the effects of other side reactions. Consequently, it has to be based on mass loss measurements for more accurate estimations. The suitability of corrosion analysis by mass losses was confirmed by AFM observations which showed that there are no deposits present on the Si surfaces after discharge experiments. Under the assumption of four electron processes, the anode mass conversion efficiencies of $\mathrm{Si}$-air batteries are limited up to $40-50 \%$ due to the substantial mass losses from side reactions. Hence, the anode mass conversion efficiency with respect discharge capacity and specific energy $\mathrm{w}_{\text {cam }}$ have to be considered as important parameters for the materials screening. Overall ranking for the As-, Sb-, and B-doped $\mathrm{Si}$ anodes based on these parameters, the $\langle 111\rangle$ oriented As-doped Si are considered to be the best choice for an anode material in Si-air batteries with $\mathrm{EMIm}(\mathrm{HF})_{2.3} \mathrm{~F}$ electrolyte. Operated at $0.1 \mathrm{~mA} / \mathrm{cm}^{2}$, the cells provide stable discharge potentials of $1.1 \mathrm{~V}$ and specific energies related the consumed anode mass of more than $1600 \mathrm{Wh} / \mathrm{kg}$.

\section{Acknowledgment}

This work was funded by the German Federal Ministry of Education and Research (BMBF) within the project AlSiBat (03SF0486C).

\section{References}

1. H. Seidel, L. Csepregi, A. Heuberger, and H. Baumgartel, J. Electrochem. Soc., 137, 3612 (1990).

2. E. D. Palik, J. W. Faust, H. F. Gray, and R. F. Greene, J. Electrochem. Soc., 129, 2051 (1982). 
3. P. Allongue, V. Costa-Kieling, and H. Gerischer, J. Electrochem. Soc., 140, 1018 (1993).

4. X. Zhong, H. Zhang, Y. Liu, J. Bai, L. Liao, Y. Huang, and X. Duan, ChemSusChem, 5, $177(2012)$

5. Y. E. Durmus, Ö. Aslanbas, S. Kayser, H. Tempel, F. Hausen, L. G. J. de Haart, J. Granwehr, Y. Ein-Eli, R.-A. Eichel, and H. Kungl, Electrochim. Acta, 225, 215 (2017).

6. D. W. Park, S. Kim, J. D. Ocon, G. H. A. Abrenica, J. K. Lee, and J. Lee, ACS Appl. Mater. Interfaces, 7, 3126 (2015).

7. R. Hagiwara, T. Hirashige, T. Tsuda, and Y. Ito, J. Fluor. Chem., 99, 1 (1999).

8. R. Hagiwara, T. Hirashige, T. Tsuda, and Y. Ito, J. Electrochem. Soc., 149, D1 (2002)

9. K. Matsumoto, R. Hagiwara, R. Yoshida, Y. Ito, Z. Mazej, P. Benkic, B. Zemwa, O. Tamada, H. Yoshino, and S. Matsubara, Dalton Trans, 144 (2004).

10. R. Hagiwara, Y. Nakamori, K. Matsumoto, and Y. Ito, J. Phys. Chem. B, 109, 5445 (2005).

11. G. Cohn and Y. Ein-Eli, J. Power Sources, 195, 4963 (2010).

12. P. Jakes, G. Cohn, Y. Ein-Eli, F. Scheiba, H. Ehrenberg, and R.-A. Eichel, ChemSusChem, 5, 2278 (2012).
13. G. Cohn, R.-A. Eichel, and Y. Ein-Eli, Phys. Chem. Chem. Phys., 15, 3256 (2013)

14. G. Cohn, D. D. Macdonald, and Y. Ein-Eli, ChemSusChem, 4, 1124 (2011).

15. B. Shvartsev, G. Cohn, H. Shasha, R.-A. Eichel, and Y. Ein-Eli, Phys. Chem. Chem. Phys., 15, 17837 (2013).

16. X. G. Zhang, Electrochemistry of Silicon and Its Oxide, Springer, New York, (2001).

17. J. Butler, Trans. Faraday Soc., 19, 734 (1924).

18. C. Wagner and W. Traud, Zeitschrift für Elektrochemie und Angew. Phys. Chemie, 44, 391 (1938).

19. T. Erdey-Gruz and M. Volmer, Zeitschrift für Phys. chemie-abteilung a-chemische Thermodyn. Kinet. Elektrochemie Eig., 150, 203 (1930).

20. O. Raz, D. Starosvetsky, T. Tsuda, T. Nohira, R. Hagiwara, and Y. Ein-Eli, Electrochem. Solid-State Lett., 10, D25 (2007).

21. O. Raz, Z. Shmueli, R. Hagiwara, and Y. Ein-Eli, J. Electrochem. Soc., 157, H281 (2010).

22. X. G. Zhang, J. Electrochem. Soc., 138, 3750 (1991).

23. H. Seidel, L. Csepregi, A. Heuberger, and H. Baumgartel, J. Electrochem. Soc., 137, 3626 (1990).

24. K. E. Petersen, Proc. IEEE, 70, 420 (1982). 